\title{
Analysis of the Influence of Wind Turbine Noise on Seismic Recordings at Two Wind Parks in Germany
}

\author{
Hortencia Flores Estrella, Michael Korn, Kilian Alberts \\ Institut für Geophysik und Geologie, Universität Leipzig, Leipzig, Germany \\ Email: hortencia.flores@uni-leipzig.de
}

How to cite this paper: Flores Estrella, H., Korn, M. and Alberts, K. (2017) Analysis of the Influence of Wind Turbine Noise on Seismic Recordings at Two Wind Parks in Germany. Journal of Geoscience and Environment Protection, 5, 76-91.

https://doi.org/10.4236/gep.2017.55006

Received: February 28, 2017

Accepted: May 19, 2017

Published: May 22, 2017

Copyright (C) 2017 by authors and Scientific Research Publishing Inc. This work is licensed under the Creative Commons Attribution International License (CC BY 4.0).

http://creativecommons.org/licenses/by/4.0/

(c) (i) Open Access

\begin{abstract}
We recorded continuous seismic noise close and around two wind parks with different geological site conditions in order to investigate the effects of wind turbines on seismic signals in the frequency interval between 1 and $10 \mathrm{~Hz}$. In wind park Fraureuth-Beiersdorf (5 turbines, $11 \mathrm{~km}$ south from Zwickau, Saxony), we used small seismic networks, with 3 to 5 stations for $1-2$ weeks. In Heinde ( 2 turbines, close to Hildesheim, Lower Saxony), we recorded 1 week with one station around $1 \mathrm{~km}$ away from the wind turbines and some additional stations for several hours only. With the spectrogram analysis of the data, we clearly identify the diurnal variation on the spectral amplitude separately from the noise generated by the turbines. The turbine noise appears at certain frequency bands around 2.2, 2.7, 3.3, 4.5, 5.2 and $6.6 \mathrm{~Hz}$. A linear relation between the spectral amplitudes of these frequency bands and the wind velocity or rotation velocity of the turbines is clearly identified. The seismic signals produced by the operation of the wind turbines are not peaks at single frequencies, but look more like frequency bands with increased noise amplitudes. They could be identified up to at least $10 \mathrm{~km}$ in the case of Fraureuth-Beiersdorf. These bands depend on numerous parameters, i.e. wind turbine height, weight and construction, number of turbines, geology, etc. In both wind parks we also recorded along profiles with increasing distances from the wind turbines. With the analysis of these data, we propose an amplitude attenuation model for the wind park Fraureuth-Beiersdorf to a distance of $9 \mathrm{~km}$, and for Heinde to a distance of $4 \mathrm{~km}$. The attenuation models for both wind parks are quite different, depending probably on the local geology and topography.
\end{abstract}

\section{Keywords}

Wind Turbine, Seismic Noise, Seismic Records 


\section{Introduction}

It is generally accepted [1] [2] [3] [4] that due to their moving masses (tower, blade rotation) the operation of wind turbines (WT) generates vibrations, which propagate in the ground as elastic waves that can be observed at large distances from the WT. Since these oscillations occur mainly in the seismically interesting frequency band $(1-10 \mathrm{~Hz})$, seismological stations aiming for the detection of local seismic events, may be significantly affected in their operation. This raises the question of banning the construction of WTs close to existing seismic stations by defining protection radii around seismic stations.

To evaluate the adverse effect of WT on seismic stations, it is necessary to quantify both the noise emissions of different types of wind turbines and the effect of local geology on the attenuation of seismic vibrations with distance.

In order to analyze the influence of signals generated by the operation of WT on seismic records, we recorded seismic noise near and around two wind parks (WP), with different kind and number of WTs and different near-surface geological conditions.

The analysis of the seismic noise measurements intends: 1) to characterize the WTs vibration emission in terms of frequency content and amplitude variation as a function of wind velocity; and 2) to quantify the amplitude decay of the WT generated signals with distance. These are steps towards the final goal of establishing simple rules for defining distance-dependent levels of WT generated noise and from that deduce protection radii around seismic stations.

In the first part of this work, we investigate the spectral characteristics of the recorded ground motion in order to identify the noise level diurnal variation, and to define which frequency bands would be affected by the signals generated by the WT operation, by correlating the spectral amplitudes with the wind velocity, or with the WT's rotor velocity. In a second section, we analyze the spectral amplitude dependency of the recorded signals with distance to the WT. In the last section, we propose an amplitude decay model with distance to the WT. By comparative measurements on two wind parks, the influence of the nearsurface geology on the seismic wave propagation could be investigated.

\section{Data}

We selected two wind parks (WP) with different kind and number of wind turbines (WT), as well as different geological conditions: WP Fraureuth-Beiersdorf (Saxony, Germany) and WP Heinde (Lowersaxony, Germany) (Figure 1).

\subsection{Wind Park Fraureuth-Beiersdorf}

The WP Fraureuth-Beiersdorf is located $70 \mathrm{~km}$ south of Leipzig, between the villages of Fraureuth and Neumark, and consists of five WTs (Figure 2). Near this WP there are several permanent seismic stations of the Saxonian Seismological Network (SXNET) and the Thuringian Seismological Network (TSN). The station Schönfels, SCHF, $\sim 4 \mathrm{~km}$ away from WP, belongs to the SXNET and 


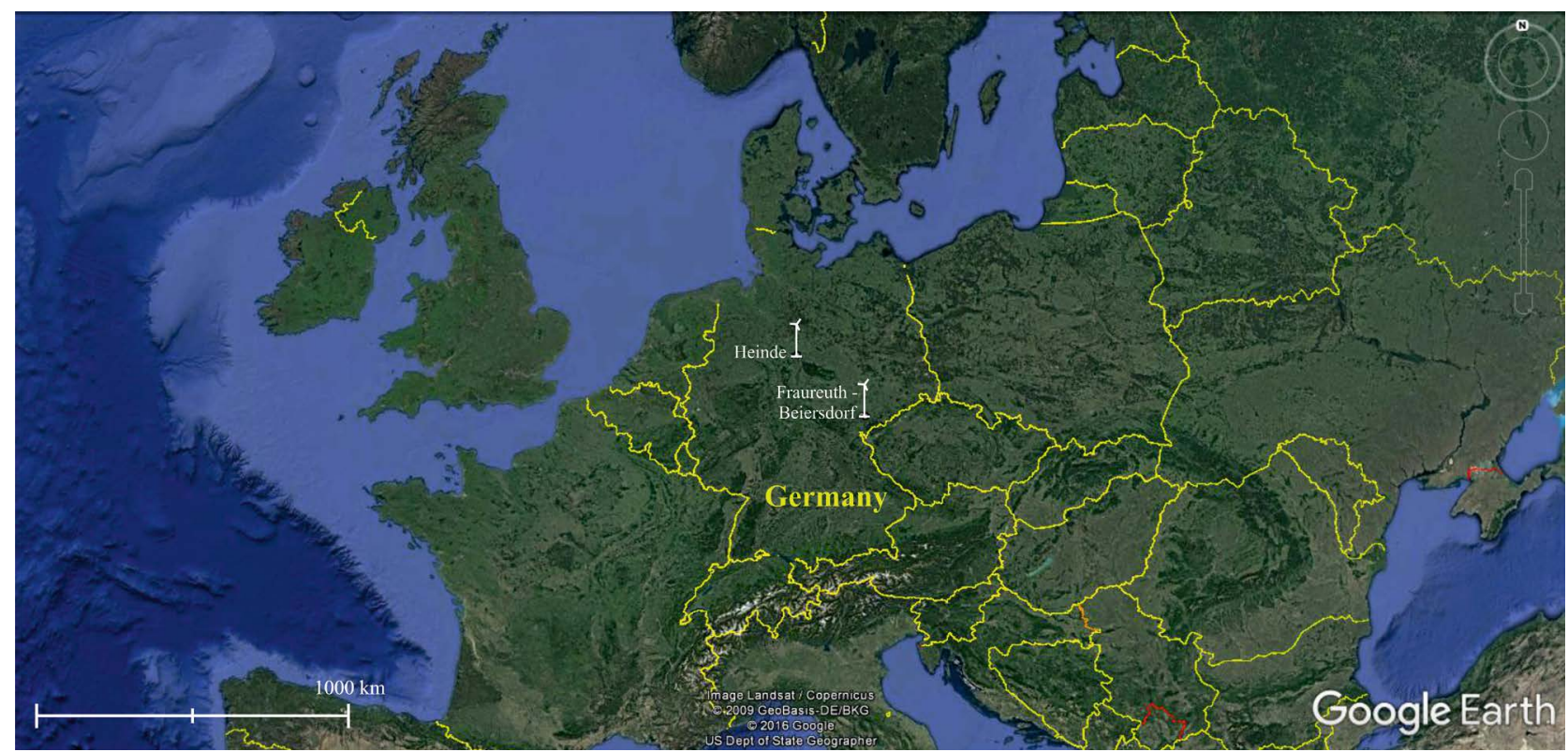

Figure 1. Wind parks Fraureuth-Beiersdorf (Saxony) and Heinde (Lowersaxony) location.

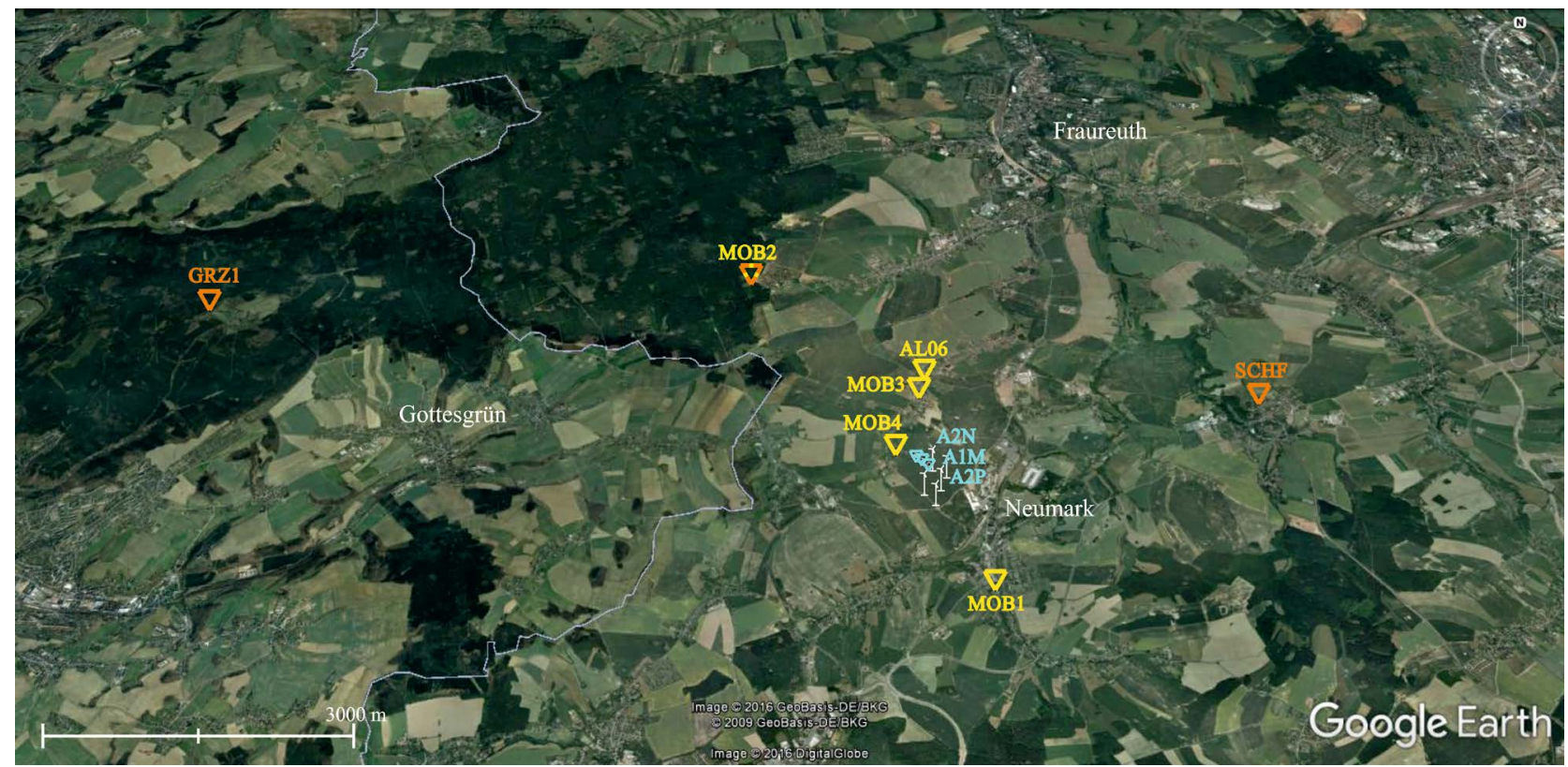

Figure 2. Wind park, Fraureuth-Beiersdorf, $70 \mathrm{~km}$ south of Leipzig. Comprising five wind turbines (white symbols). In November 2015, five stations were installed around the WP: MOB1 to MOB4 and AL06 (yellow triangles), with distances between 560 and $3800 \mathrm{~m}$ from the northern most WT. The stations A2P, A1M and A2N (blue triangles) recorded during 2 hours in May 2016, with distances of 10, 110 and $210 \mathrm{~m}$ from the WT. Due to the good data quality of station MOB2, it stayed as a permanent station of the Thuringian Seismological Network. The stations SCHF and GRZ1 are permanent stations of the Saxonian and the Thuringian Seismological Networks, respectively. The details about the campaigns are listed in Table 1.

stations MOB2, and Greiz, GRZ1, $3.8 \mathrm{~km}$ and $\sim 9.1 \mathrm{~km}$ away, respectively, are part of the TSN (Figure 2).

We carried out three measurement campaigns (see Figure 2, Figure 3 and Table 1). Since the data quality from Station MOB2 (3.8 km away from the WP) was quite good, it remained as a permanent station. Additionally to the seismic 


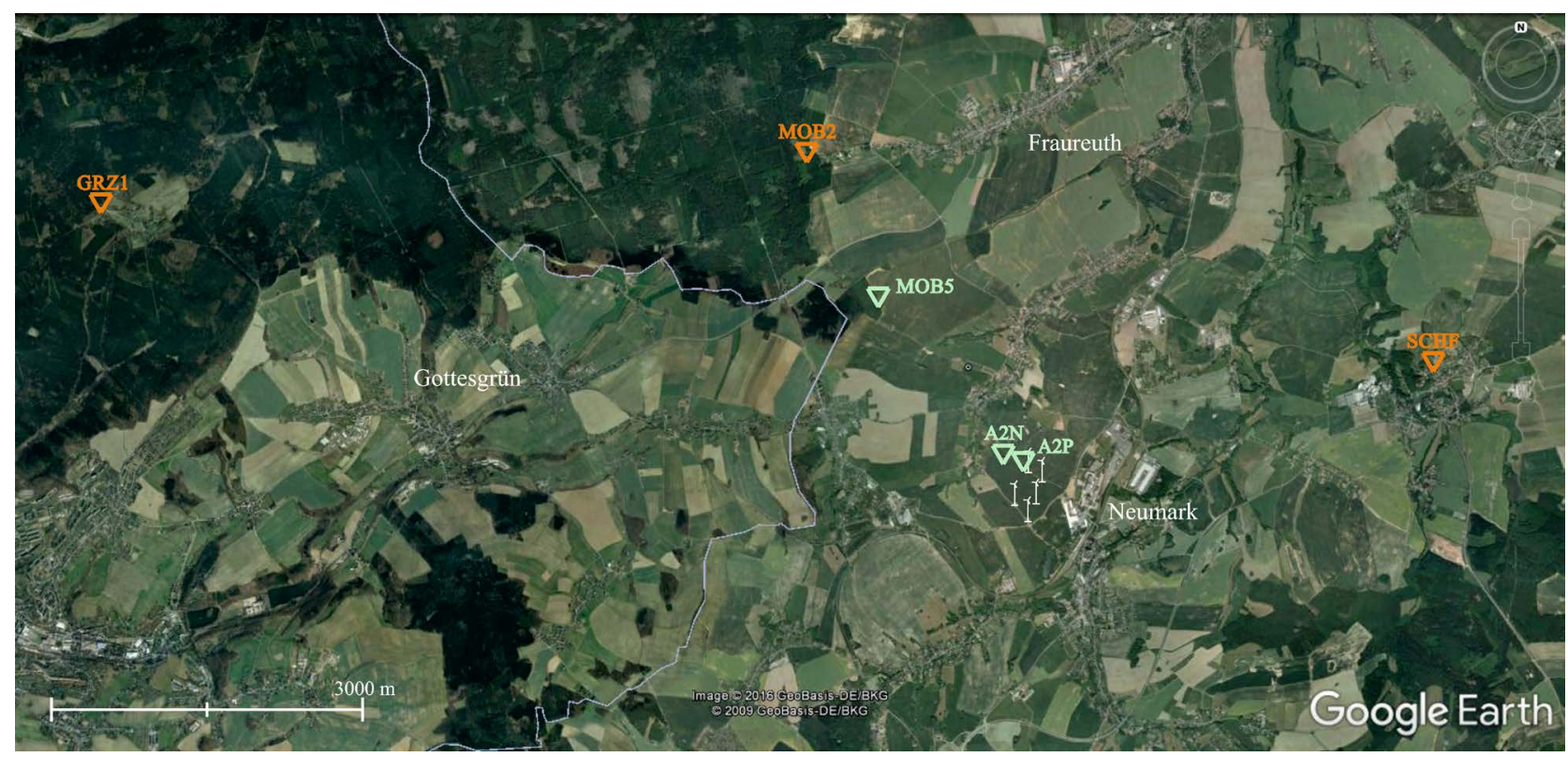

Figure 3. Third measurement campaign near WP Fraureuth-Beiersdorf. The orange triangles indicate the location of the permanent stations MOB2, SCHF and GRZ1. The green triangles indicate the position of the stations A2P, A2N, MOB3, MOB5 and A1M, which recorded during 2 hours in August 2016. The details about the campaign are listed in Table 1.

Table 1. Measurement campaigns near the WP Fraureuth-Beiersdorf. Distances to the northern WT are measured with GPS. The duration refers to the time the stations recorded simultaneously.

\begin{tabular}{|c|c|c|c|c|}
\hline \multicolumn{5}{|c|}{ Wind park Fraureuth-Beiersdorf } \\
\hline Date (dd.mm.yyyy) & Number of stations & Station name & Distance to the northern WT [m] & Duration \\
\hline \multirow{5}{*}{ 07.11.2015-20.11.2015 } & \multirow{5}{*}{5} & MOB4 & 560 & \multirow{5}{*}{7 to 13 days } \\
\hline & & MOB3 & 1300 & \\
\hline & & MOB1 & 1500 & \\
\hline & & AL06 & 1600 & \\
\hline & & MOB2 & 3800 & \\
\hline \multirow{6}{*}{15.05 .2016} & \multirow{6}{*}{6} & $\mathrm{~A} 2 \mathrm{P}$ & 10 & \multirow{6}{*}{2 hours } \\
\hline & & $\mathrm{A} 1 \mathrm{M}$ & 110 & \\
\hline & & $\mathrm{A} 2 \mathrm{~N}$ & 210 & \\
\hline & & MOB2 (permanent) & 3800 & \\
\hline & & SCHF (permanent) & 4000 & \\
\hline & & GRZ1 (permanent) & 9100 & \\
\hline \multirow{6}{*}{01.08 .2016} & \multirow{6}{*}{6} & $\mathrm{~A} 2 \mathrm{P}$ & 7 & \multirow{6}{*}{2 hours } \\
\hline & & $\mathrm{A} 2 \mathrm{~N}$ & 330 & \\
\hline & & MOB5 & 2000 & \\
\hline & & MOB2 (permanent) & 3800 & \\
\hline & & SCHF (permanent) & 4000 & \\
\hline & & GRZ1 (permanent) & 9100 & \\
\hline
\end{tabular}

noise records, wind velocity data are also available from a meteorological station about $3 \mathrm{~km}$ from the WP.

With the first measurement campaign, the seismic noise around the WP was recorded during 7 to 13 days, in order to define the noise spectral characteristics and the relation with the wind velocity. The other two measurement campaigns aimed at determining the distance-dependent decay of WT generated noise. 
Therefore, the setup was along profiles with increasing distance to the WP, with relatively constant wind velocity conditions during 2 hours.

\subsection{Wind Park Heinde}

The WP Heinde is located near $45 \mathrm{~km}$ south of Hannover, just $700 \mathrm{~m}$ south of highway A7. Thus, strong seismic noise not generated by the WTs could be expected. This WP consists of two identical WTs. In this study case we had access to the wind velocity data measured directly by the WT, as well as to the blade rotation velocity and power generation data. We selected the southern WT as reference because is the more distant from the Freeway A7.

The measurements were carried out in July 2016 and August 2016 along profiles in a southerly direction, 10 to $4000 \mathrm{~m}$ away from the southern WT (Figure 4 and Table 2) for 2 hours. The station A1M (Figure 4 in light green) recorded 1 week to analyze the noise temporal variation.

\section{Noise Amplitude vs. Wind Velocity}

\subsection{Wind Park Fraureuth-Beiersdorf}

Figure 5 shows the spectrogram for the three motion components of the station MOB4 (560 m away from the WP) for a measurement period of 1 week in November 2015. This figure illustrates the power spectral density as a function of time. At the bottom of the figure the wind velocity from the station Lichtentanne, $3 \mathrm{~km}$ away from the WP, is shown.

In the spectrograms, several horizontal bands of increased amplitude can be identified around the frequencies $2.7,3.3,5.2$ and $6.6 \mathrm{~Hz}$. The intensity of these

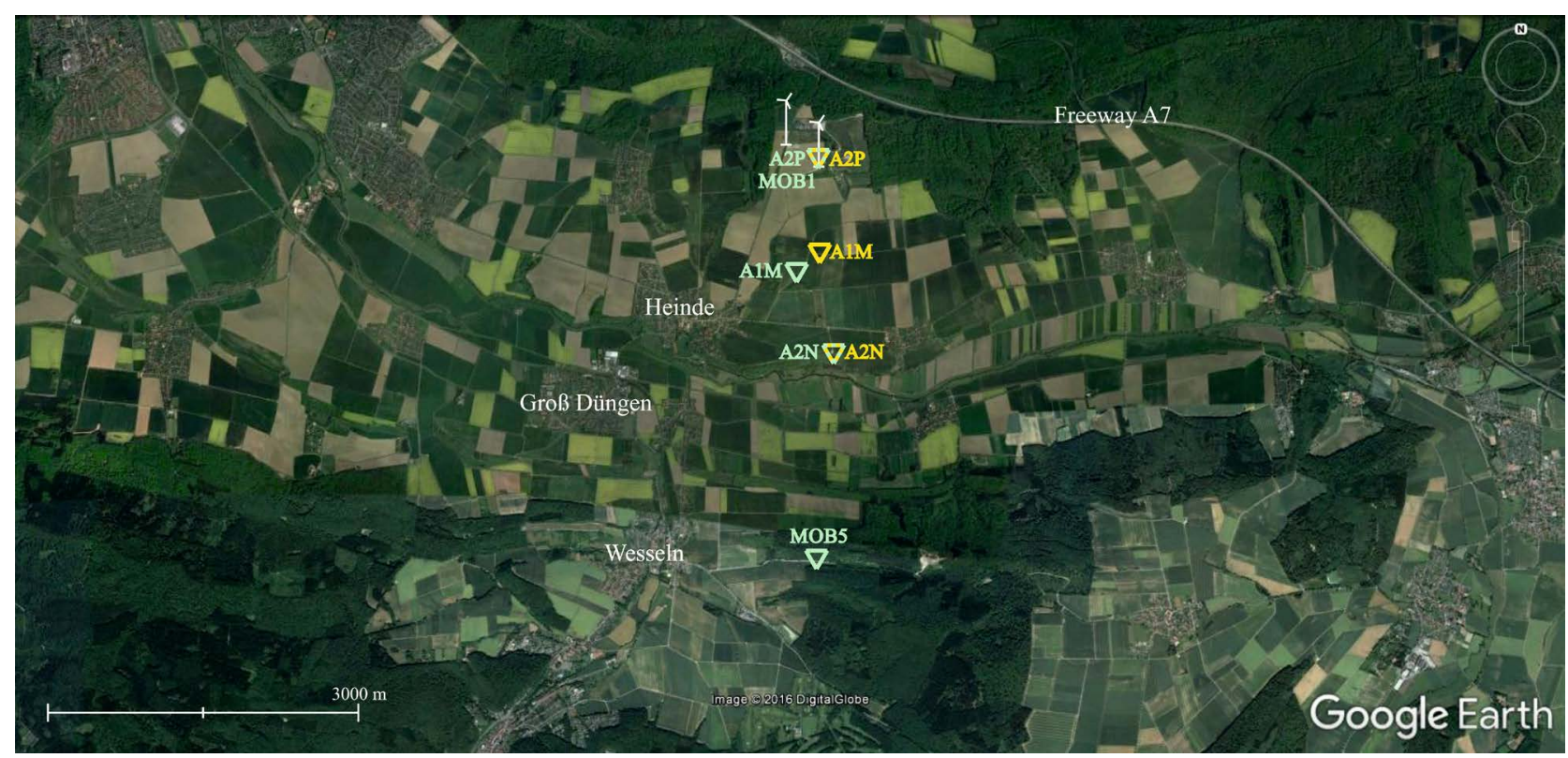

Figure 4. Measurement campaigns at WP Heinde, near $45 \mathrm{~km}$ to the south of Hannover. During the first campaign, the stations were located at 10, 1000 and $2000 \mathrm{~m}$ from the wind turbine to the south (yellow triangles). The second campaign recorded with four stations with distances of $10 \mathrm{~m}, 1.2,2$ and $4 \mathrm{~km}$ (green triangles). Station A1M of the second campaign recorded during 1 week in order to analyze the noise temporal variation. 
Table 2. Measurement campaigns near WP Heinde. Distances from the southern WT are measured with GPS. The duration refers to the time the stations recorded simultaneously.

\begin{tabular}{|c|c|c|c|c|}
\hline \multicolumn{5}{|c|}{ Wind park Fraureuth-Heinde } \\
\hline Date (dd.mm.yyyy) & Number of stations & Station name & Distance to the southern WT [m] & Duration \\
\hline \multirow[t]{2}{*}{14.07 .2016} & \multirow[t]{2}{*}{3} & $\mathrm{~A} 1 \mathrm{M}$ & 1000 & \multirow[t]{2}{*}{2 hours } \\
\hline & & $\mathrm{A} 2 \mathrm{~N}$ & 2000 & \\
\hline \multirow{3}{*}{03.08 .2016} & \multirow{3}{*}{4} & $\mathrm{~A} 1 \mathrm{M}$ & 1200 & \multirow{3}{*}{2 hours } \\
\hline & & $\mathrm{A} 2 \mathrm{~N}$ & 2000 & \\
\hline & & MOB5 & 4000 & \\
\hline $03.08 .2016-12.08 .2016$ & 1 & $\mathrm{~A} 1 \mathrm{M}$ & 1200 & 6 days \\
\hline
\end{tabular}

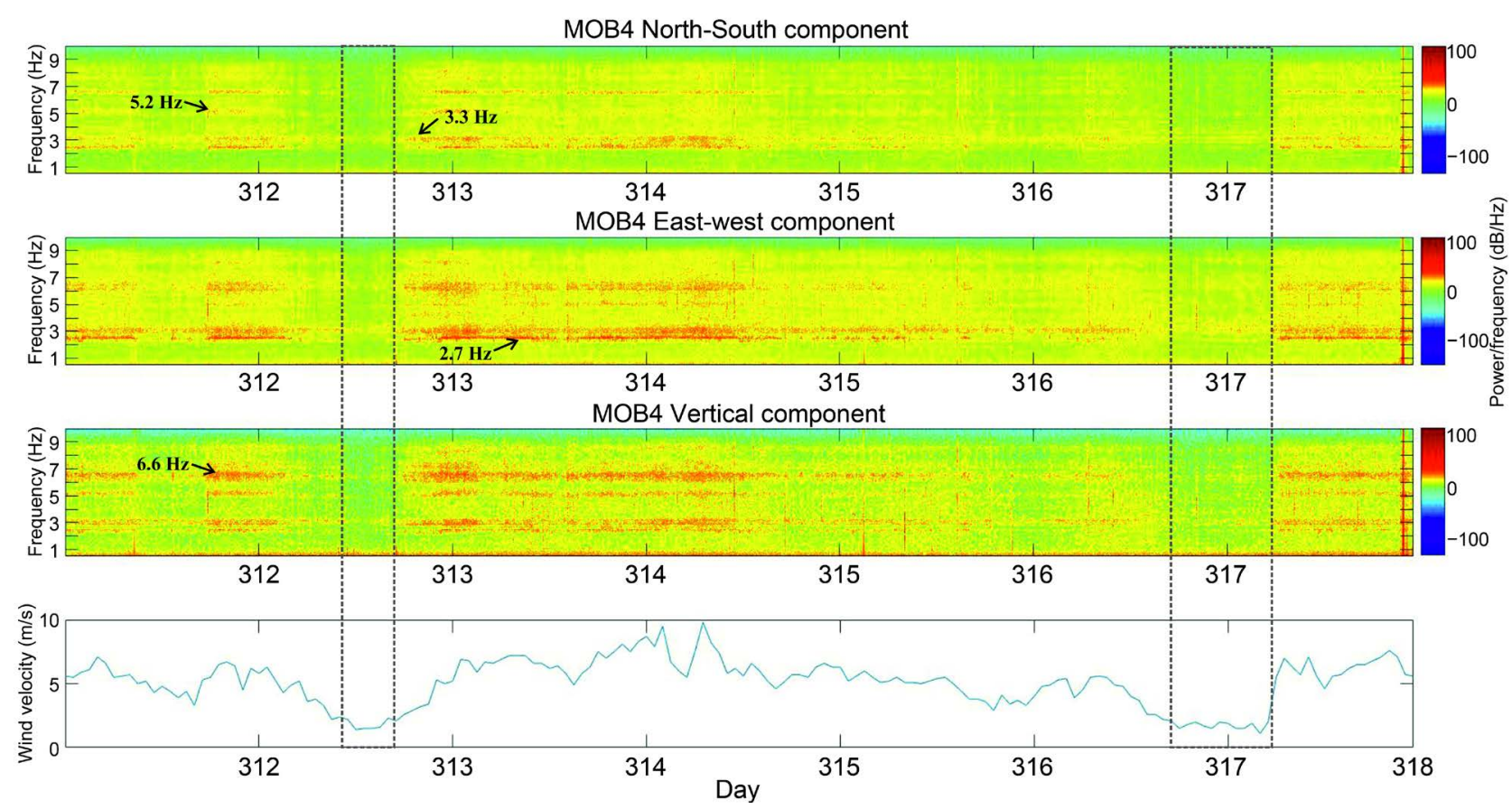

Figure 5. Spectrogram for the three motion components of station MOB4 on WP Fraureuth-Beiersdorf (560 m distance from the WT to the north), for a one week measurement. At the bottom, the wind velocity recorded by the meteorological station Lichtentanne ( $3 \mathrm{~km}$ away from WP) is shown. The intensity of the bands around the frequencies $2.7,3.3,5.2 \mathrm{und} 6.6 \mathrm{~Hz}$ correlates very well with the wind velocity; moreover, these bands disappear for time windows with low wind velocities (black dotted rectangles). The horizontal scale is given in Julian days: day $311 \hat{=} 07.11 .2015$, day $318 \hat{=} 14.11 .2015$. The time marks indicate 0 hour UTC.

bands correlates well with the wind velocity. For slow wind velocities (blackframed time windows), these bands disappear completely. A possible explanation is that the WT shut down for wind velocities lower than $4 \mathrm{~m} / \mathrm{s}$.

\subsection{Wind Park Heinde}

For the measurements in WP Heinde we had access to the wind velocity data measured directly by the wind turbines, as well as to the blade rotation velocity (Figure 6). These values correlate very well and it can be seen that for velocities lower than $4 \mathrm{~m} / \mathrm{s}$ the wind turbines do not rotate. 


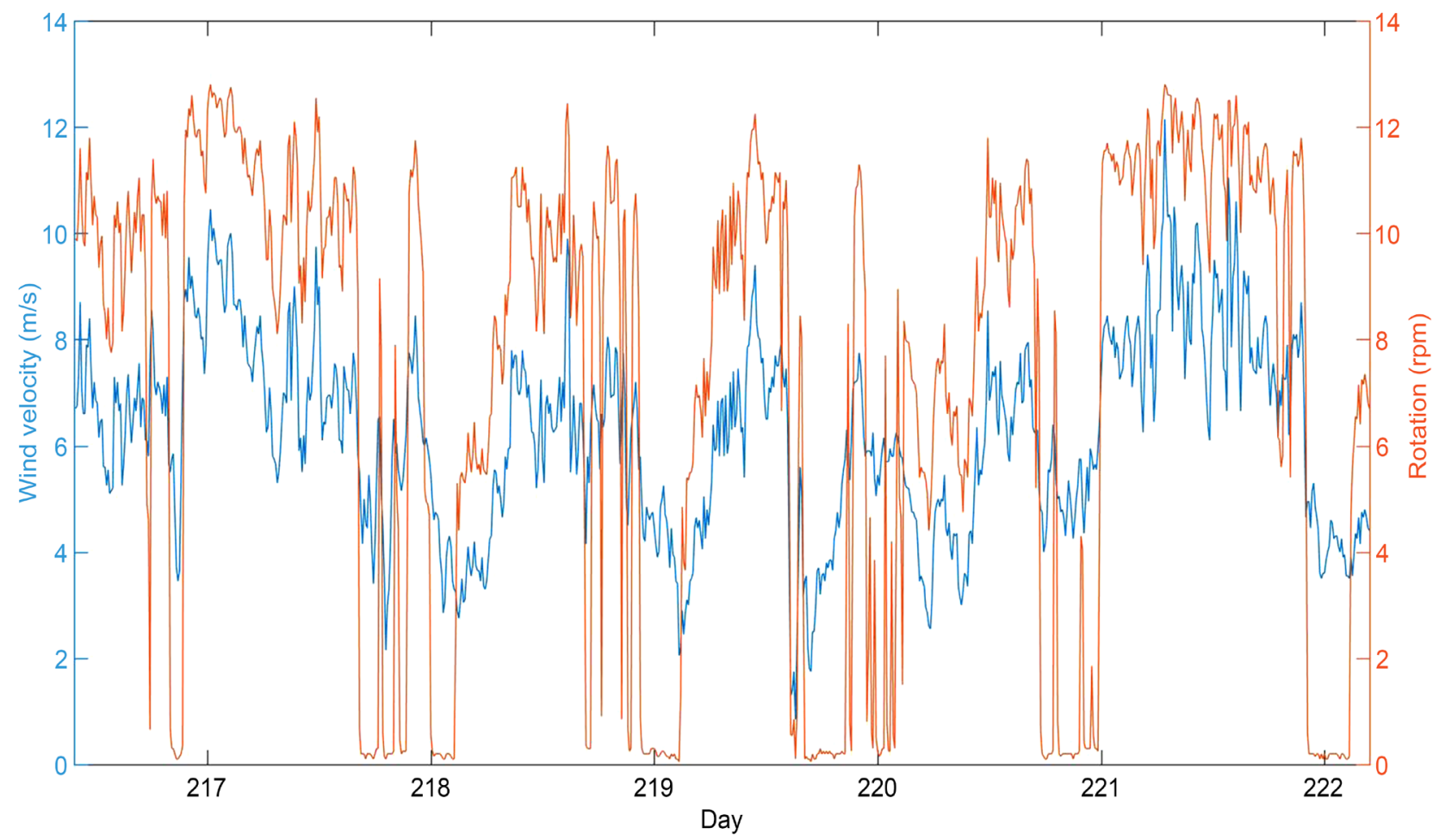

Figure 6. Wind velocity (blue) and blade rotation velocity (orange) measured directly by the wind turbines for one week measurement period in WP Heinde. The horizontal axis is given in Julian days: day $217 \triangleq 04.08 .2016$, day $222 \triangleq 09.08 .2016$. The time marks indicate 0 hour UTC.

Figure 7 shows the spectrogram for the three motion components of station A1M (1200 m away from WP). At the bottom of the figure, the wind velocity and the blade rotation velocity are displayed. The spectrograms indicate a strongly day-dependent noise level for the frequency interval between 2 and 10 $\mathrm{Hz}$, which is due to the proximity of the highway A7, only $700 \mathrm{~m}$ to the north of the WP (Figure 4). Additionally, bands with increased amplitudes can be identified around 2.7 and $4.5 \mathrm{~Hz}$, which are independent of the noise diurnal variation and correlate very well with the blade rotation velocity. Therefore, these frequencies could be recognized as noise generated by the WT (red framed time windows). Furthermore, in time windows when the rotation velocity is zero, the mentioned frequency bands disappear (black framed time window).

For frequencies smaller than $2 \mathrm{~Hz}$ there is no visible information, mainly because of the $4.5 \mathrm{~Hz}$ geophones that were used for the measurement.

The fact that the frequency signals of the WTs can still be clearly identified at a very noisy location shows that they are very significant disturbances, which could lead to a considerable reduction of the data quality of seismological stations.

In both parks it was possible to distinguish the signals generated by the WT operation from the "normal" seismic noise as high amplitude frequency bands, which appear when WT operates and disappear when there is no WT rotation, or when the wind velocity is slower than the cut off wind velocity for WT. 


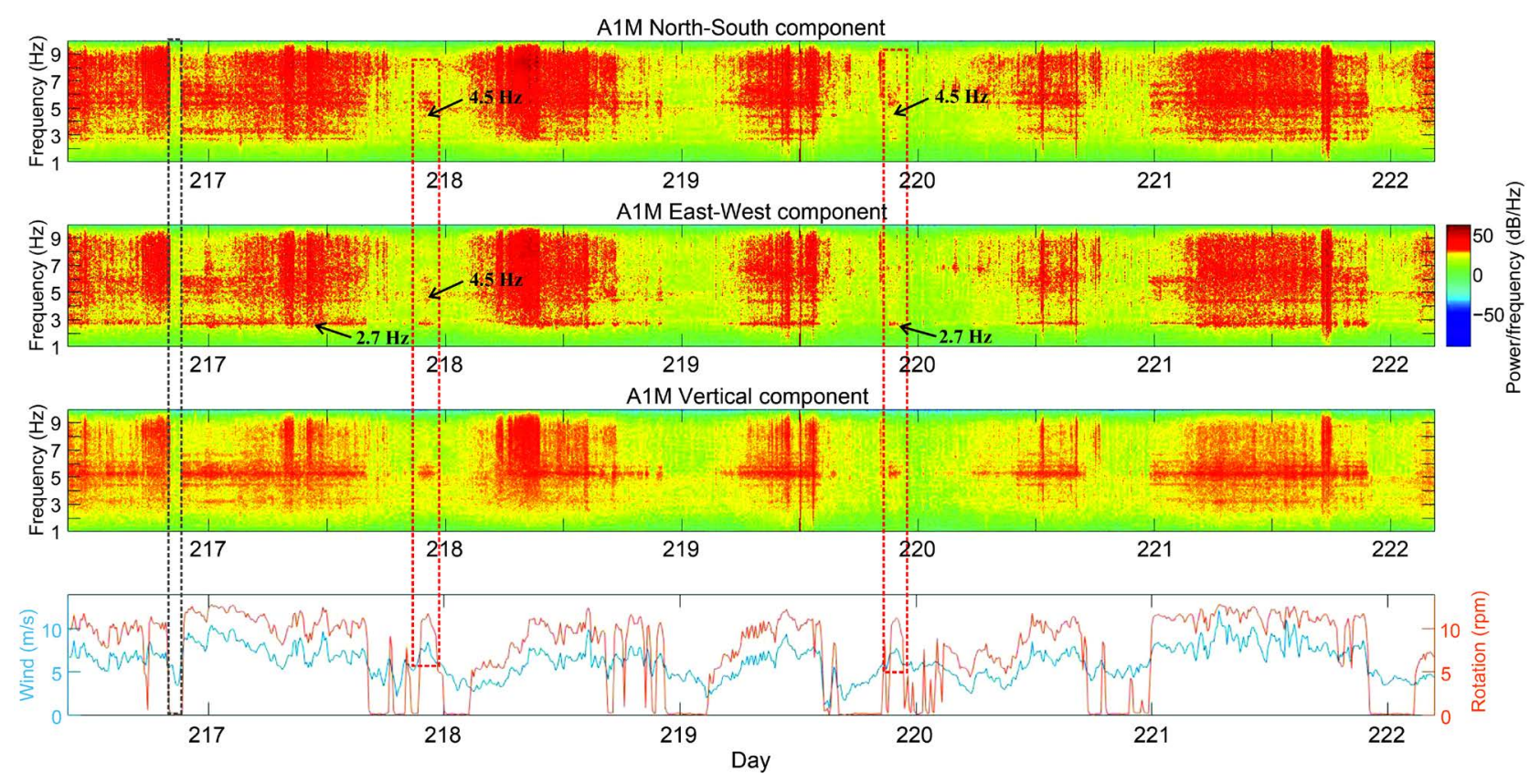

Figure 7. Spectrogram for the three motion components of station A1M (1200 m away from WP) for a one week measurement period. At the bottom of the figure, the wind velocity (blue) and the blade rotation velocity (orange) are shown. There is a strong diurnal variation of noise-level, due to the proximity of the highway A7. However, it is possible to identify high amplitude frequency bands, near 2.7 and $4.5 \mathrm{~Hz}$, which do not depend on this diurnal variation. Moreover, the black-framed time window indicates a short period with null rotation; the high amplitude bands by 2.7 and $4.5 \mathrm{~Hz}$ disappear in these periods. On the contrary, the red framed time windows indicate short periods with high rotation velocities, where the high amplitudes by 2.7 and $4.5 \mathrm{~Hz}$ appear. The horizontal axis is given in Julian days: day $217 \bumpeq 04.08 .2016$, day $222 \bumpeq 09.08 .2016$. The time marks indicate 0 hour UTC.

\section{Spectral Analysis}

\subsection{Wind Park Fraureuth-Beiersdorf}

Two profile measurements took place near the WP Fraureuth-Beiersdorf (Table 1); Figure 8 and Figure 9 show the amplitude spectra of the individual stations for the profiles in May 2016 and in August 2016, respectively. Additionally, the permanent stations MOB2, SCHF and GRZ1 were also included in the analysis. Figure 9 shows the vertical amplitude spectra of the stations where broadband seismographs operated.

The high amplitude around $3.3 \mathrm{~Hz}$ can be clearly identified in all spectra (Figure 8 and Figure 9). Further peaks at $1.1 \mathrm{~Hz}, 3.7 \mathrm{~Hz}, 4.0 \mathrm{~Hz}, 4.4 \mathrm{~Hz}, 4.8-5$ $\mathrm{Hz}, 6.5 \mathrm{~Hz}, 7.2 \mathrm{~Hz}, 8.1 \mathrm{~Hz}$ and $8.7 \mathrm{~Hz}$ are only partially visible. Especially the peaks near $1.1 \mathrm{~Hz}$ are well identifiable in the broadband seismographs (Figure 9).

In Figure 8 and Figure 9, the spectral amplitude decay with the distance of the peak located on the frequency band around $3.3 \mathrm{~Hz}$ peak can be clearly seen. This peak is still detectable up to $10 \mathrm{~km}$ distance from the WP (Station GRZ1)

\subsection{Wind Park Heinde}

At the WP Heinde, two profile measurements were carried out on July 2016 and August 2016 for 2 hours each (Table 2). Since the wind velocities were similar 


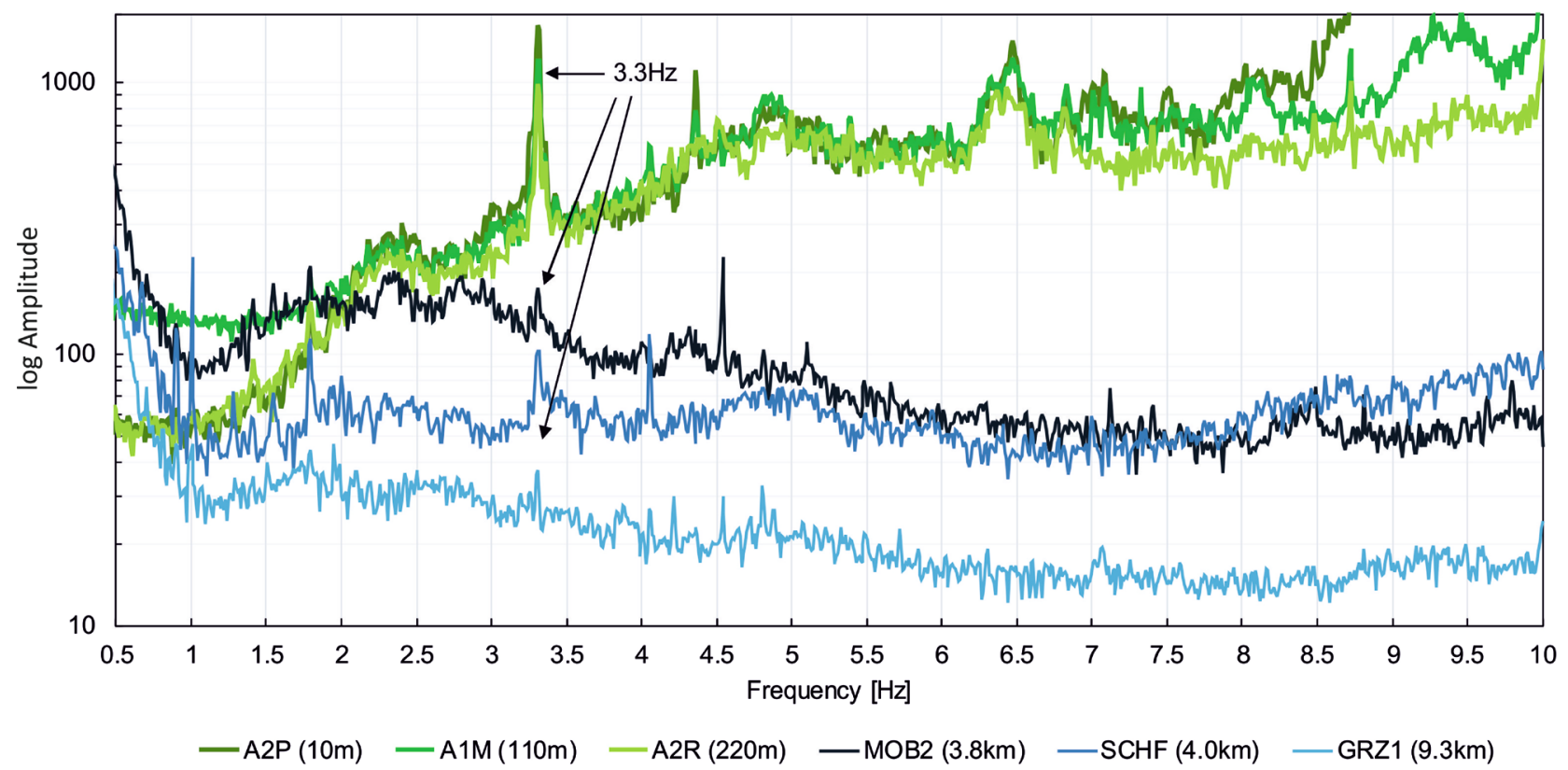

Figure 8. Amplitude spectra for the vertical motion components of the stations that recorded on 19.05.2016. The band around 3.3 $\mathrm{Hz}$ has a marked high amplitude, it is identifiable in all stations and its amplitude decreases clearly with the distance. Other bands with high amplitudes around $1.1 \mathrm{~Hz}, 4.0 \mathrm{~Hz}, 4.4 \mathrm{~Hz}, 6.5 \mathrm{~Hz}, 7.2 \mathrm{~Hz}$ and $8.1 \mathrm{~Hz}$ are visible just in some of the stations.

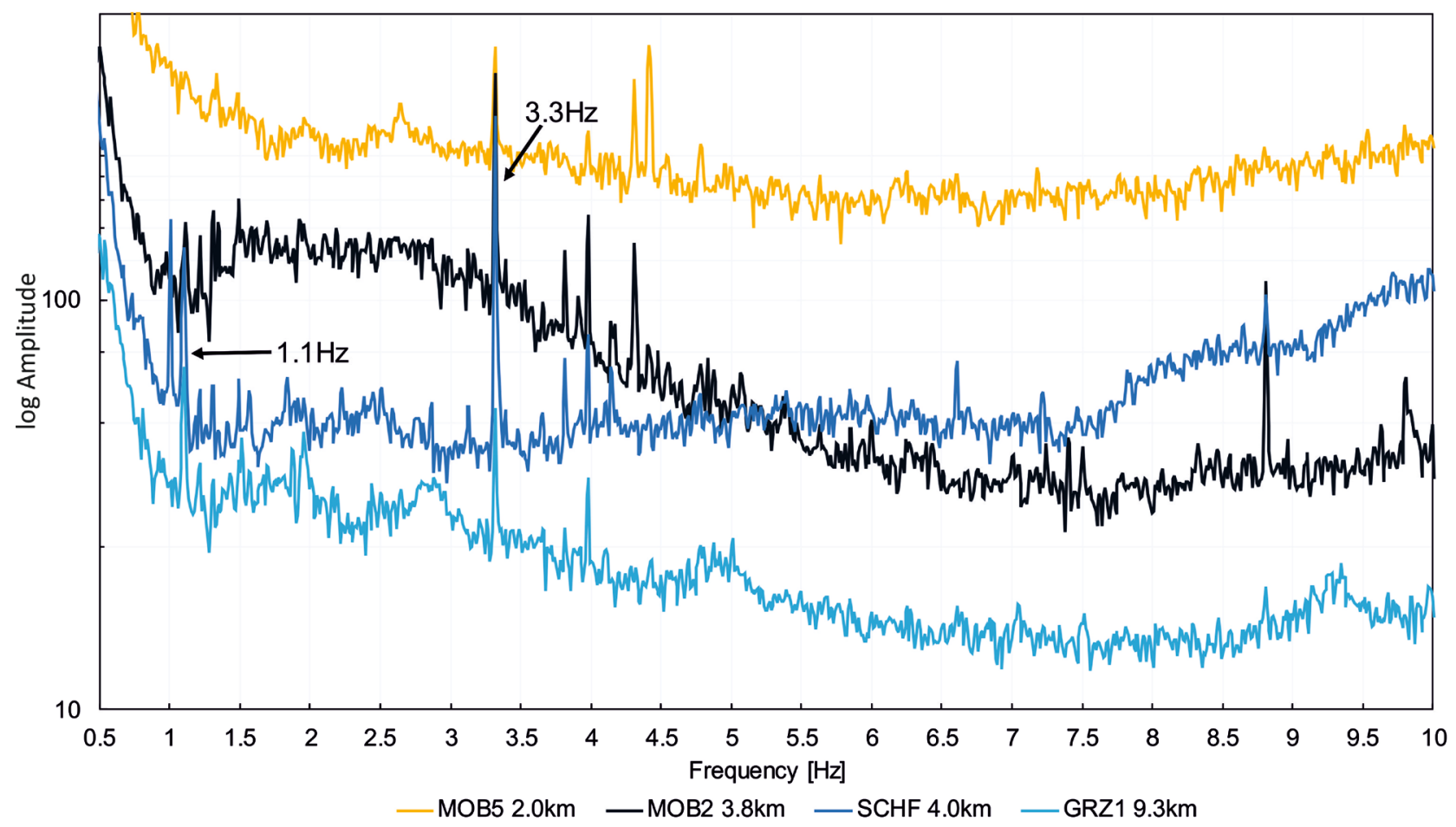

Figure 9. Amplitude spectra for the vertical motion components of the broadband stations that recorded on 01.08.2016. The band around $3.3 \mathrm{~Hz}$ has a marked high amplitude, it is visible in all stations and its amplitude decreases clearly with the distance. Other bands with high amplitudes around $1.1 \mathrm{~Hz}, 3.7 \mathrm{~Hz} .4 .0 \mathrm{~Hz}, 4.2 \mathrm{~Hz}, 4.8 \sim 5 \mathrm{~Hz}, 6.5 \mathrm{~Hz}, 7.2 \mathrm{~Hz}$ und $8.7 \mathrm{~Hz}$ are visible just in some of the stations.

on both days (Figure 10), the amplitude spectra are shown and discussed together (Figure 11 and Figure 12). 


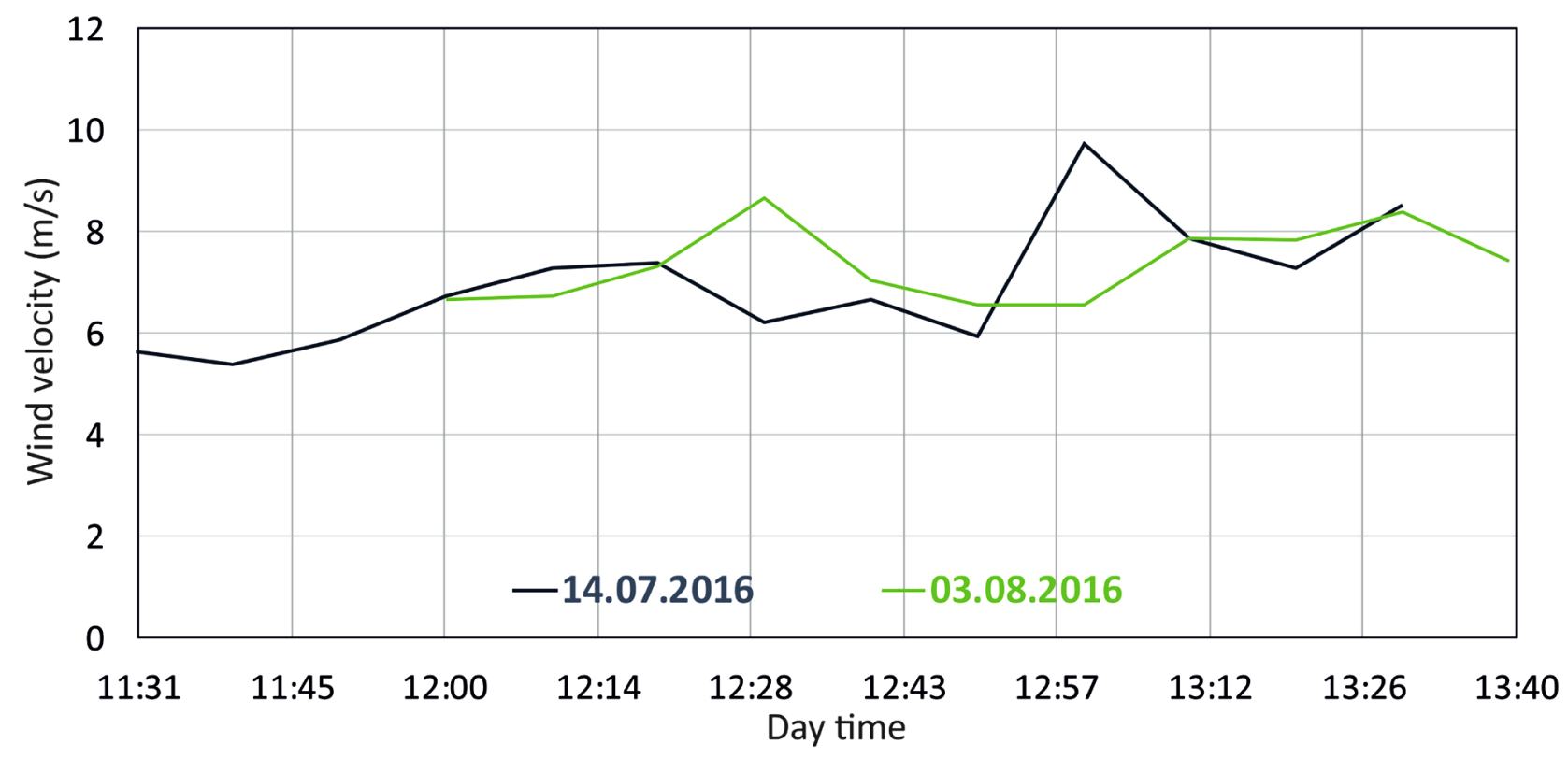

Figure 10. Wind velocity in WP Heinde for the two measurements on 14.07.2016 and 03.08.2016.

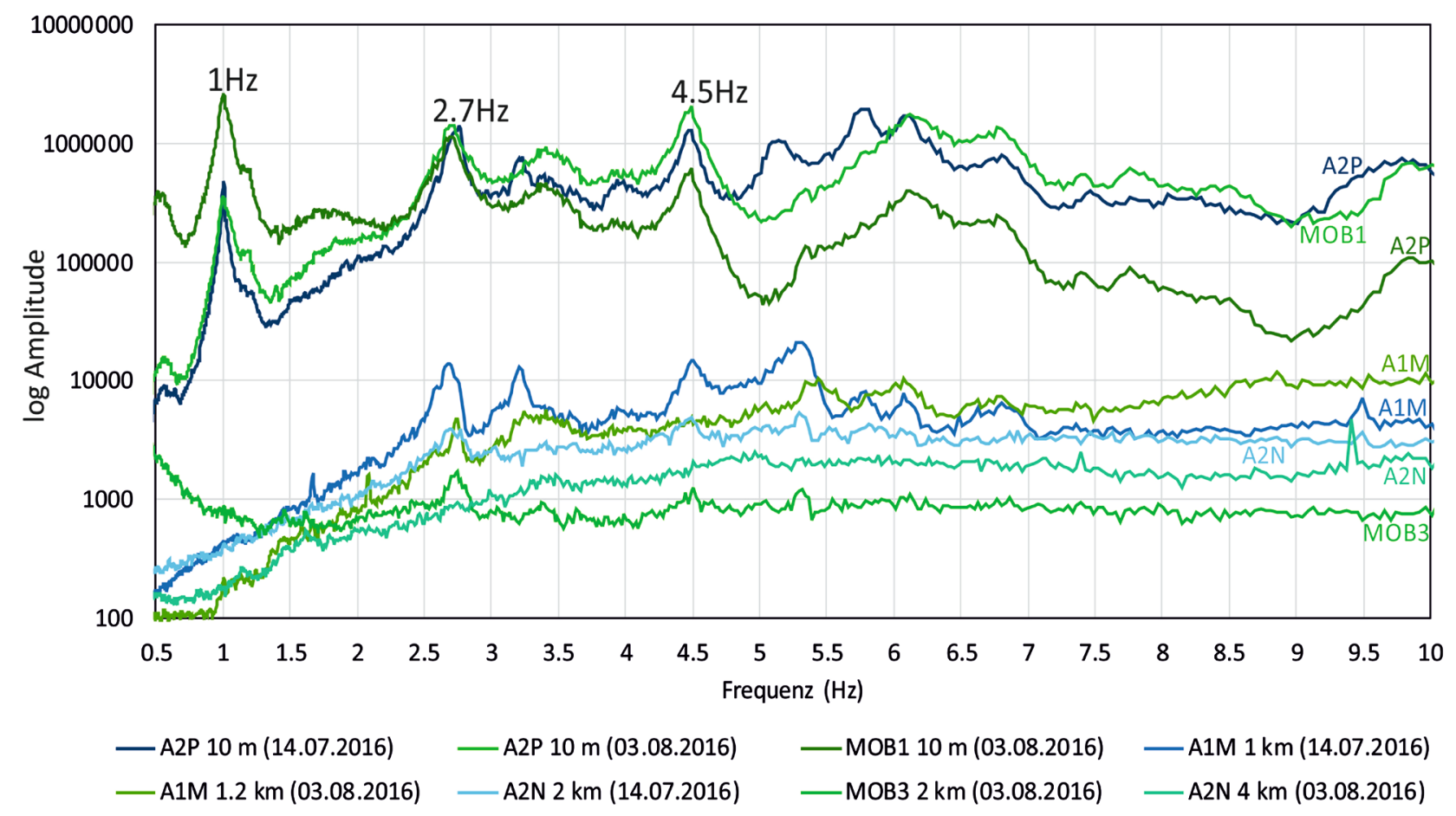

Figure 11. Amplitude spectra for the vertical motion components of the stations along the profiles on July and August, 2016 (Table 2). The bands around 1, 2.7 and $4.5 \mathrm{~Hz}$ have a marked high amplitude. Especially, the bands near $2.7 \mathrm{and} 4.5 \mathrm{~Hz}$ are visible in all stations and its amplitude decreases clearly with the distance.

Figure 11 shows the amplitude spectra for the vertical motion components of the stations located between $10 \mathrm{~m}$ and $4 \mathrm{~km}$ away from the WTs. The stations A2P and MOB1 show three frequency bands with large amplitudes at $1 \mathrm{~Hz}, 2.7$ $\mathrm{Hz}$ and $4.5 \mathrm{~Hz}$. The frequency band at $1 \mathrm{~Hz}$ probably depends on the movement of the WKAs tower [1] [2] [3] [4]. 


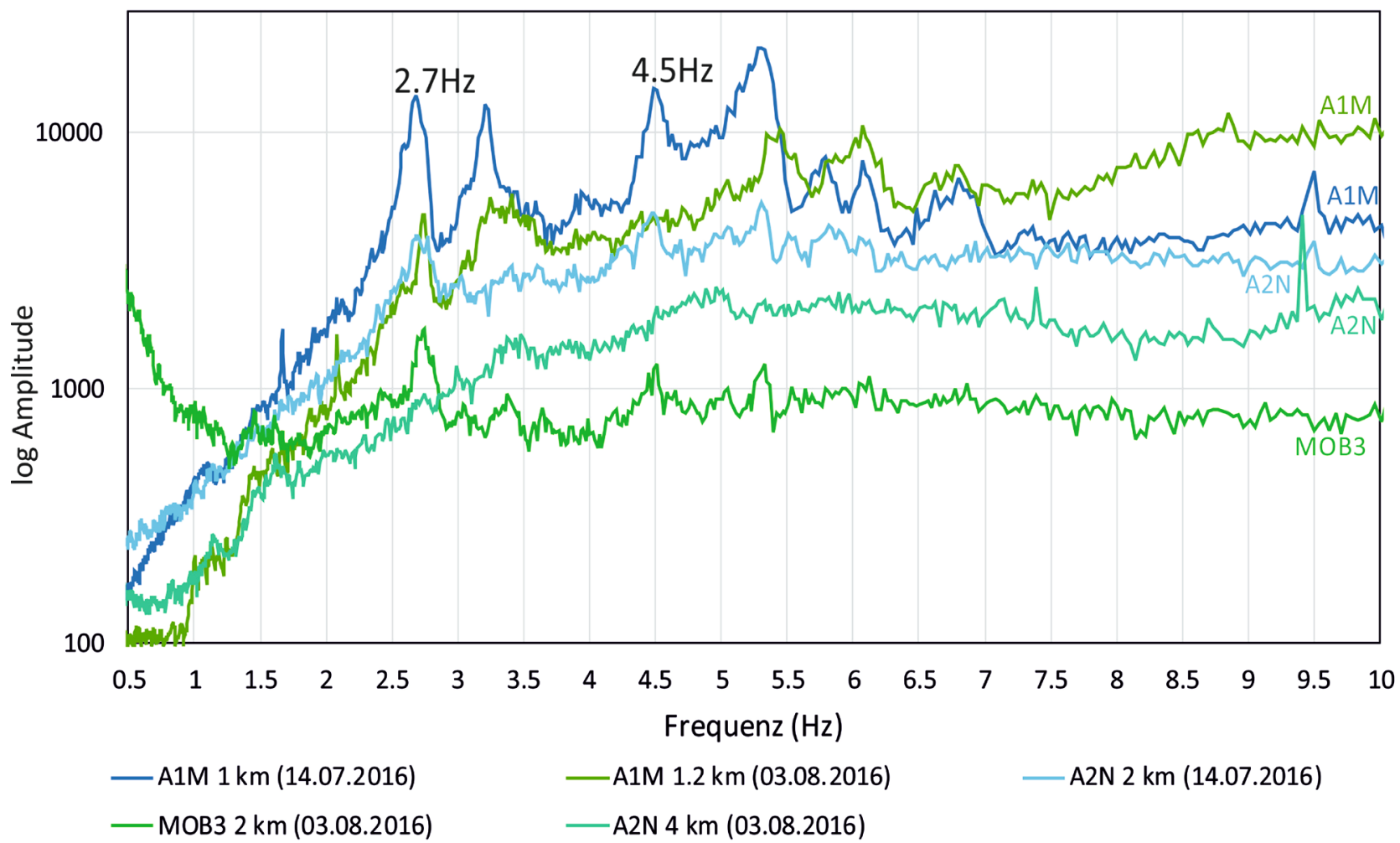

Figure 12. Amplitude spectra for the vertical motion components of the stations that recorded by WP Heinde, with distances larger than $1 \mathrm{~km}$, to avoid the near-wave-field effect recorded next to the WT (stations at $10 \mathrm{~m}$ distance). The spectra for the two measurements campaigns are shown, blue lines indicate the measurement on July 2016 and the green lines the one on August 2016 (Table 2).

The station MOB1 recorded with a broadband seismogram, while the station A2 $\mathrm{N}$ recorded with a $4.5 \mathrm{~Hz}$ geophone, this explains the amplitude difference for the $1 \mathrm{~Hz}$ frequency. It is noteworthy that at $2.7 \mathrm{~Hz}$ the geophones and the broadband seismometer measure the same amplitudes, showing that the measurements with $4.5 \mathrm{~Hz}$ geophones are valid still for frequencies $\sim 2.7 \mathrm{~Hz}$.

Figure 12 shows the amplitude spectra of stations with a distance of $1 \mathrm{~km}$ from the WP, in order to avoid the near-wave-field close to the WT (stations at $10 \mathrm{~m}$ distance). The amplitude decay of the bands around $2.7 \mathrm{~Hz}$ and $4.5 \mathrm{~Hz}$ with distance from the WTs is evident.

The $1 \mathrm{~Hz}$ frequency band observed mainly in the Fourier spectra of the nearest stations for WP Heinde and on the broadband stations for WP FraureuthBeiersdorf is probably related with the movement of the tower, and it has been reported by previous studies [1] [2] [3] [4].

The other high amplitude frequency bands are not equal for the two WPs, which leads to the question which parameters could play a role on the WT disturbances generation. The main differences between the two WPs are: 1) the number of WTs, five for Fraureuth-Beiersdorf and two for Heinde. 2) WT type, which mainly cares about the height, and how the blades move. In WP Fraureuth-Beiersdorf there are three WT types, with different heights between 44 and $53 \mathrm{~m}$. In WP Heinde there are two identical WTs $120 \mathrm{~m}$ high. 


\section{Distance-Dependent Decay of the Spectral Amplitudes for the Frequency Bands Generated by the WTs}

From the seismic noise spectral analysis it was possible to identify the frequency bands that are most affected by the WT generated signals. Moreover, from the measurements along profiles, the amplitude decay with the distance to the turbines was qualitatively identifiable in both WPs.

In order to obtain an energy decay model from the 2-hour profile measurements we selected the frequency band near $3.3 \mathrm{~Hz}$ for WP Fraureuth-Beiersdorf and the frequency bands around 2.7 and $4.5 \mathrm{~Hz}$ for WP Heinde.

The procedure to measure the spectral amplitude for each station is shown in Figure 13. This figure is also useful to show that the signals generated by the WT operation increase the noise amplitude in frequency bands, and not in single frequencies. Therefore, it is not possible to filter the seismic signals to avoid the WT disturbances without losing valuable information in a certain frequency range.

Figure 14, Figure 15 and Figure 16 show the mean values of the measured spectral amplitudes in the frequency bands defined for each WP, including the calculated standard deviations as a function of the distance to the WTs. These figures also show a power law model for the amplitude decay with the distance with the form:

$$
A=C / r^{\alpha}
$$

where $A$ refers to the spectral amplitude, $C$ is a constant, $r$ is the distance and $\alpha$ is the power law exponent.

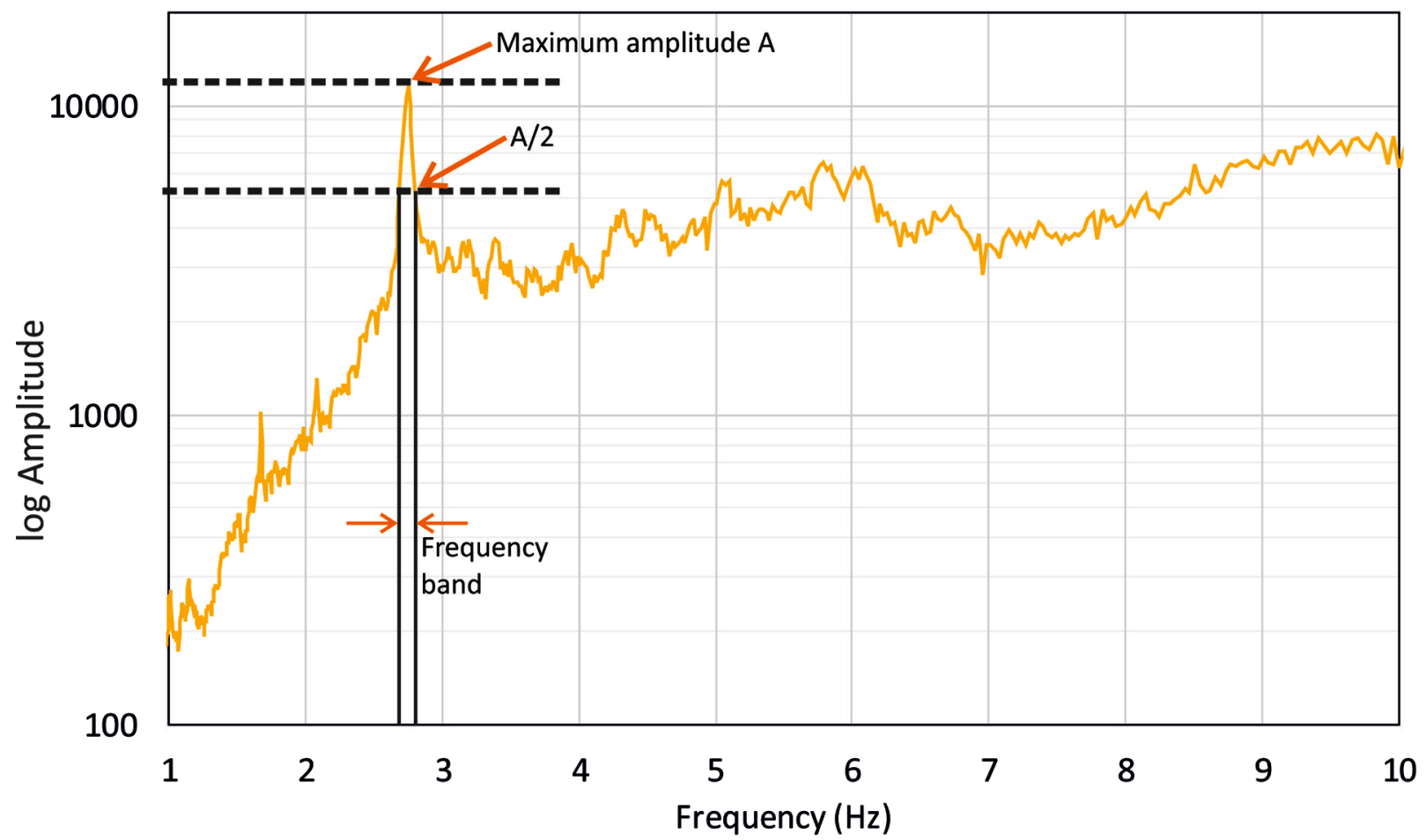

Figure 13. Spectral amplitude measurement for the energy decay analysis. This procedure was made for each station in both WPs. 


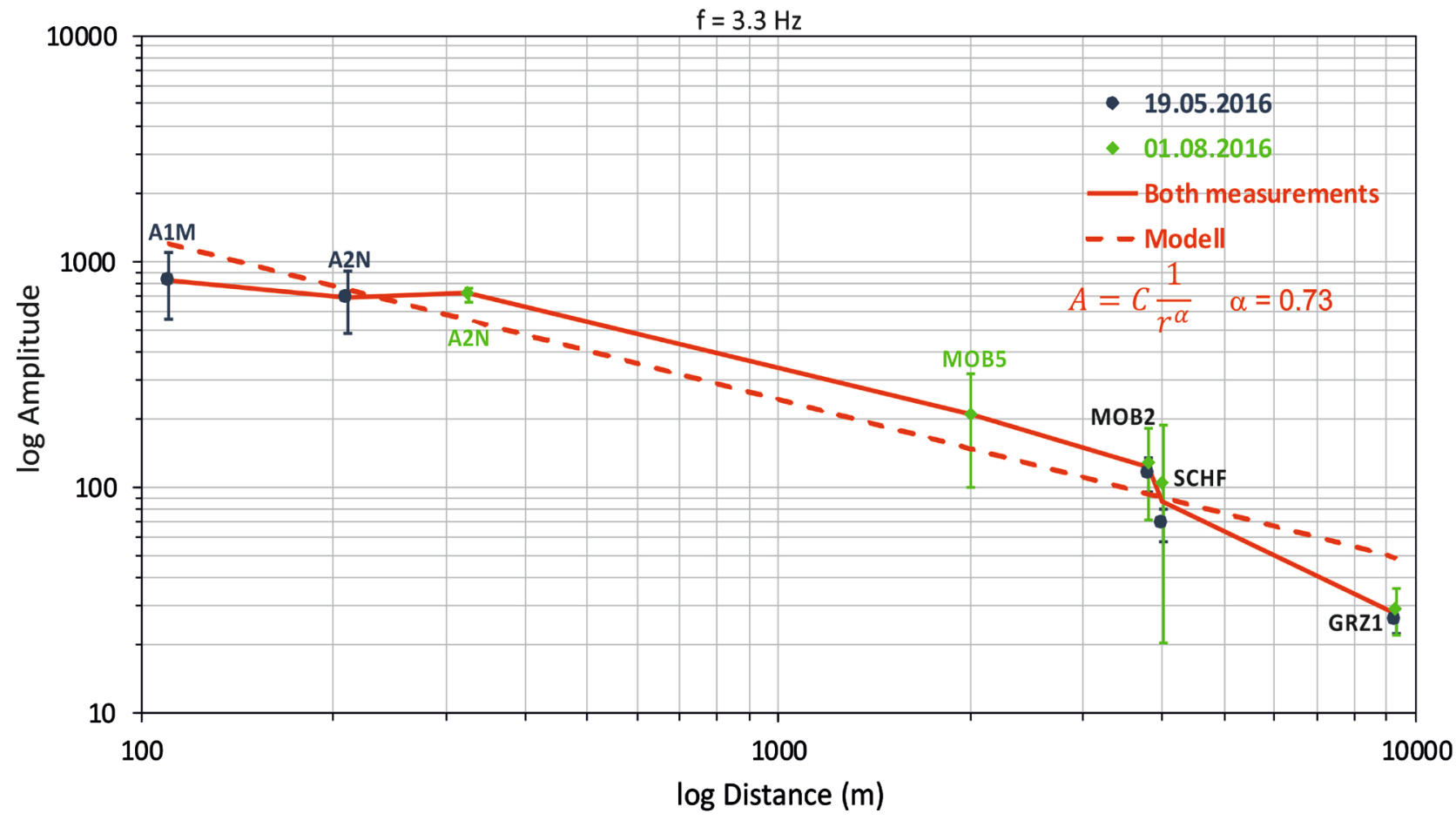

Figure 14. Spectral amplitudes decay with the distance for the WP Fraureuth-Beiersdorf, for the frequency band around $3.3 \mathrm{~Hz}$. The blue points correspond to the measurement on May 2016 and the green diamonds to the records from August 2016. The stations SCHF, MOB2and GRZ1 are permanent stations from the Seismological Networks of Saxony and of Thuringia. The error bands on each point correspond to the standard deviation of the average spectral amplitude over the frequency band around 3.3 $\mathrm{Hz}$ (Figure 13).

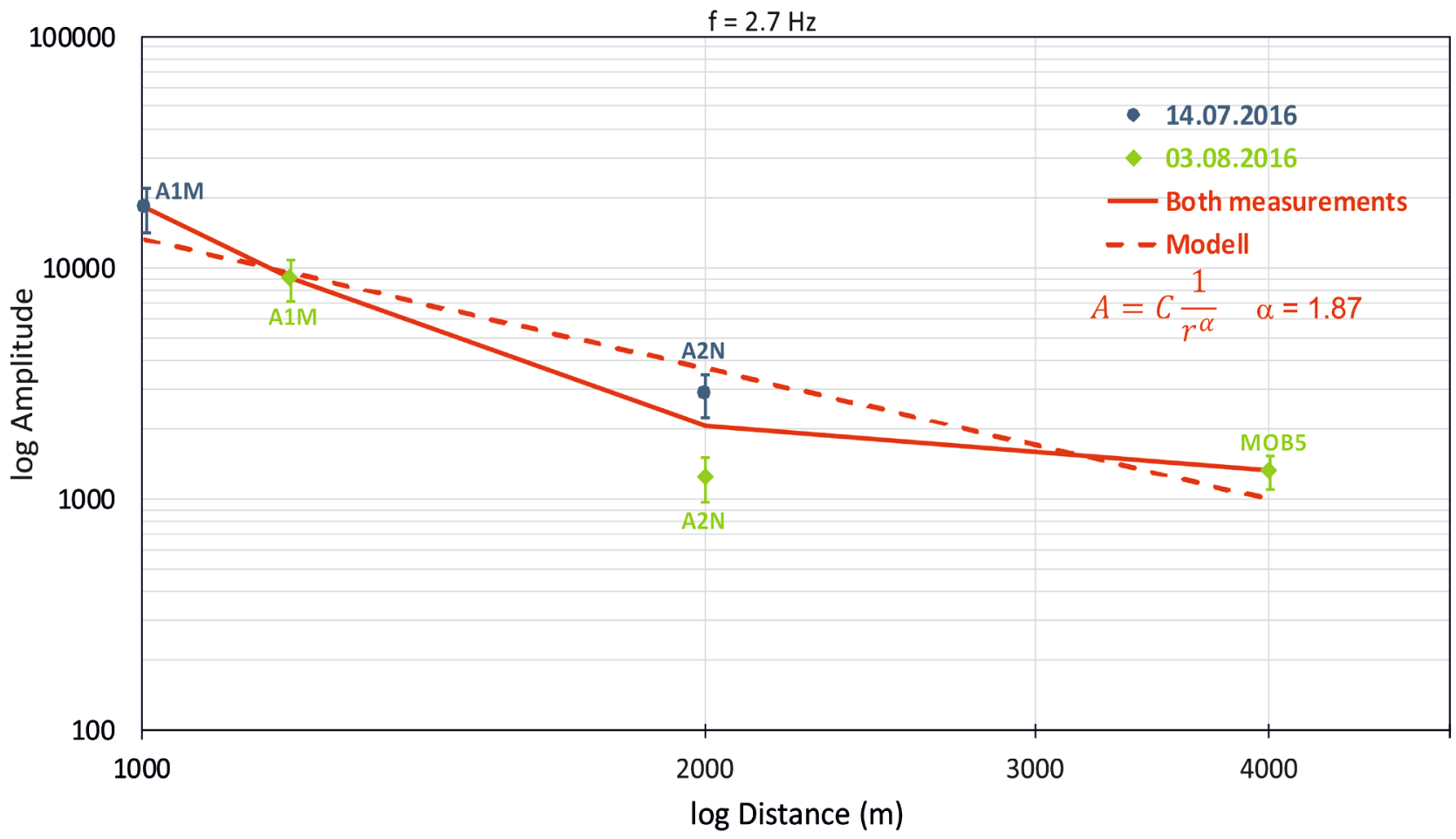

Figure 15. Spectral amplitudes decay with the distance for WP Heinde, for the frequency band around $2.7 \mathrm{~Hz}$. The blue points correspond to the measurement on July 2016 and the green diamonds to the records from August 2016. The error bands on each point correspond to the standard deviation of the average spectral amplitude over the frequency band around $2.7 \mathrm{~Hz}$. 


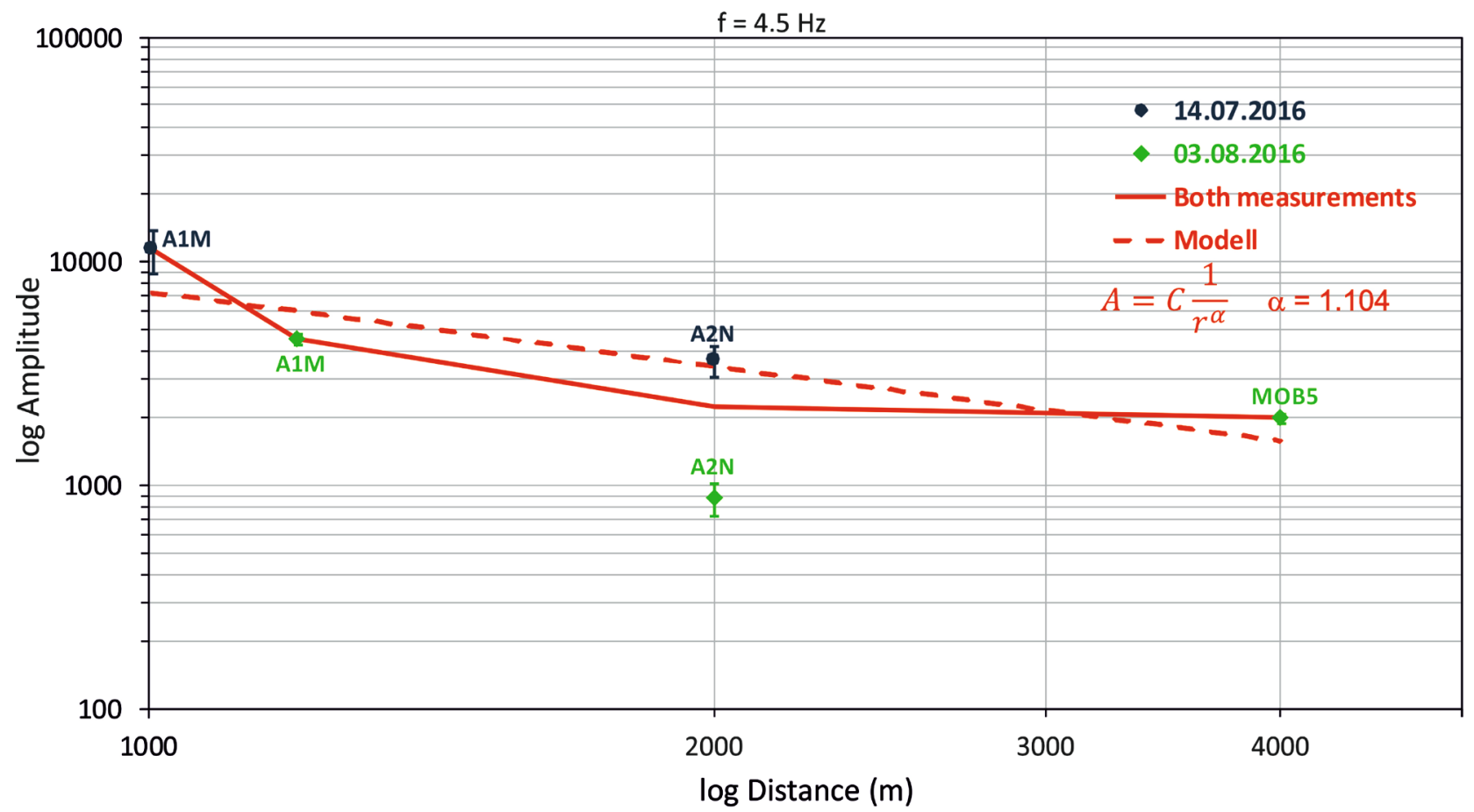

Figure 16. Spectral amplitudes decay with the distance for WP Heinde, for the frequency band around $4.5 \mathrm{~Hz}$. The blue points correspond to the measurement on July 2016 and the green diamonds to the records from August 2016. The error bands on each point correspond to the standard deviation of the average spectral amplitude over the frequency band around $4.5 \mathrm{~Hz}$.

The error bands at each point in Figure 14, Figure 15 and Figure 16 refer to the standard deviation of the average amplitude over each frequency band (Figure 13).

For WP Fraureuth-Beiersdorf (Figure 14) we show the spectral amplitude decay for the measurements that took place on Mai, 2016 (19.05.2016, blue points) and August, 2016 (01.08.2016, green diamonds) (Table 1), with recording points at 110,210,330, 2000, 3800, 4000 and 9100 meters.

For the energy decay with the distance in WP Heinde, we considered two recording locations from the measurement on July 2016 (14.07.2016, blue points in Figure 15 and Figure 16) and three locations from the measurement on $\mathrm{Au}$ gust 2016 (03.08.2016, green diamonds in Figure 15 and Figure 16). In Figure 10 it can be seen that the wind velocity during the two measurement campaigns was similar; therefore, we consider the average value of the spectral amplitudes for the location $\mathrm{A} 2 \mathrm{~N}$ that was located at the same position in both campaigns (red continuous line in Figure 15 and Figure 16).

The amplitude decay with the distance models show different behaviors for the two WPs with $a$ ranging from 0.7 to 1.9. For ideally elastic surface waves propagation $\alpha=0.5$ and for body waves propagation $\alpha=1.0$ would be expected.

The observed $\alpha$-values of 0.73 at WP Fraureuth-Beiersdorf therefore points to the generation of surface waves with some energy loss by anelasticity of the subsoil and by scattering at 3D heterogeneity. The much larger attenuation at WP Heinde with $\alpha=1.87$ can hardly be explained by high anelastic losses, but rather by the presence of topographical features like a river valley just south of stations 
A2N/A2P. This requires further investigation.

\section{Conclusions}

The operation of wind turbines generates seismic noise with preferential frequencies, which can be identified as spectral bands with increased amplitude in the Fourier spectra of the ground seismic noise. Since these bands lie within the seismologically interesting frequencies $(1 \mathrm{~Hz}-10 \mathrm{~Hz})$, they can be a significant interfering signal for seismological stations for earthquake monitoring.

The intensity of the interfering signal (amplitude of the frequency band) is directly dependent on the rotor velocity, i.e. at standstill the signal disappears. The frequencies of these high amplitude bands may be dependent on the type of wind turbines; in particular, they are probably related to the height of the tower and of the moving mass.

The interfering signals produced by the operating WT could be detected up to distances of approximately $10 \mathrm{~km}$ at the WP Fraureuth-Beiersdorf. This is consistent with previous studies [4].

The amplitude decay with distance is different at the examined WPs and presumably depends on the near-surface geology, the topography and the damping of the seismic waves. The wave field propagation modeling in different subsurface structures will give a better understanding on these dependencies.

For a given WT, it should be possible to define excitation frequencies and excitation intensity of seismic noise depending on the individual construction, height etc. Intensity will additionally scale with wind velocity. Distance-dependent attenuation laws for different subsurface conditions can be found from modelling and calibrated with measurements like the ones presented here. With these ingredients, a prediction of the noise level that will be generated from future WTs at specific sites becomes into reach. This will help to define a protection radius for seismic stations that exist before the construction of a WT that can easily be used by authorities.

\section{Acknowledgements}

We thank Dr. O. Krentz for the continuous discussion and support to this work. We thank H. Melaku, J. Umlauft, E. Sondermayer, S. Brandenburg and D. Schönwald for their support and enthusiasm on the field measurements. This research was partially financed by the Saxonian Office for Environment, Agriculture and Geology.

\section{References}

[1] Schofield, R. (2002) Seismic Measurements at the Stateline Wind Project-A Prediction of the Seismic Signal that the Proposed Maiden Wind Project Would Produce at LIGO. University of Oregon, Eugene, Oregon, USA. LIGO-T020104-00-Z

[2] Styles, P., Stimpson, I., Toon, S., England, R. and Wright, M. (2005) Microseismic and Infrasound Monitoring of Low Freqency Noise und Vibrations from Windfarms. Recommendations on the Siting of Windfarms in the Vicinity of Eskdalemuir, Scotland. Report, Keele University, Keele. 
[3] Saccorotti, G., Piccinini, D., Cauchie, L. and Fiori, I. (2011) Seismic Noise by Wind Farms: A Case Study from the VIRGO Gravitational Wave Observatory, Italy. Bulletin of the Seismological Society of America, 101, 568-578. https://doi.org/10.1785/0120100203

[4] Stammler, K. andCeranna, L. (2016) Influence of Wind Turbines on Seismic Records of the Gräfenberg Array. Seismological Research Letters, 87, 1075-1081.

Submit or recommend next manuscript to SCIRP and we will provide best service for you:

Accepting pre-submission inquiries through Email, Facebook, LinkedIn, Twitter, etc. A wide selection of journals (inclusive of 9 subjects, more than 200 journals)

Providing 24-hour high-quality service

User-friendly online submission system

Fair and swift peer-review system

Efficient typesetting and proofreading procedure

Display of the result of downloads and visits, as well as the number of cited articles

Maximum dissemination of your research work

Submit your manuscript at: http://papersubmission.scirp.org/

Or contact gep@scirp.org 